\title{
Seasonal Variation in Volatile Oil, Polyphenol Content and Antioxidant Activity in Extract of Laurus nobilis Grown in Iran
}

\author{
Atefeh Bahmanzadegan ${ }^{1}$, Vahid Rowshan ${ }^{1}$, Faraneh Zareian $^{1}$, Reza Alizadeh ${ }^{2}$ and Mohammad Bahmanzadegan ${ }^{3}$ \\ ${ }^{I}$ Department of Natural Resources, Fars Research Center for Agriculture and Natural Resources, Shiraz, PO Box 71555-617, Iran \\ ${ }^{2}$ Department of Chemistry, Faculty of science, Qom University, Qom, PO Box 3714846314, Iran \\ ${ }^{3}$ Department of Mechanical engineer, Faculty of science, Jahrom University, Jahrom, PO Box 7413766171, Iran
}

\begin{abstract}
The leaves of Laurus nobilis were collected in the middle of four seasons (spring, summer, autumn, and winter) to determine the best harvesting time for obtaining the highest oil yield, 1,8-cineole and polyphenol content and antioxidant activity. After drying the plant materials in shade, their EOs (essential oils) were obtained by hydro-distillation method. Analysis of variance showed harvesting time had significant effect on the oil yields of L. nobilis. Seventy one components were identified in the oils of $L$. nobilis with 1 , 8-cineole $(5.7 \%-42.6 \%), \quad \alpha$-terpinyl acetate $(3.2 \%-13.1 \%)$, sabinene $(2.3 \%-12.0 \%)$, beta-elemene $(0.2 \%-17.7 \%)$ and (E)-caryophyllene $(0.2 \%-16.9 \%)$ as the main constituents in different seasons. The predominant phenolic constituents in L. nobilis were cinnamic acid, carvacrol, quercetin and coumarin, respectively. Gallic acid, catechin, caffeic acid, chloregenic acid, p-Comaric acid and rutin were not detected in any seasons. The best antioxidant activity was in spring $(268.6 \mu \mathrm{g} / \mathrm{mL})$ and the lowest one was in winter $(702.1 \mu \mathrm{g} / \mathrm{mL})$.
\end{abstract}

Key words: Laurus nobilis, EO, seasonal variation, polyphenol, antioxidant.

\section{Introduction}

Laurus nobilis L. belongs to the family Lauraceae, which comprises numerous aromatic and medicinal plants [1]. Laurus nobilis L. native to Mediterranean regions is also known as sweet bay, bay laurel, Grecian laurel, true bay, and bay. Laurus nobilis L. is an evergreen shrub indigenous to the south parts of Europe and the Mediterranean area. It is cultivated in the north of Iran [2]. In Iranian folk medicine, the leaves of this plant have been used to treat epilepsy [2, 3], neuralgia and parkinsonism [3]. The essential oil obtained from its leaves has been used for relieving hemorrhoid and rheumatic pains [2]. It also has diuretic $[2,3]$, antifungal [4] and antibacterial [5] activities. Leaves of this plant produce a yellow oil known for

Corresponding author: Atefeh Bahmanzadegan, master, research field: science of phytochemistry. E-mail: bahmanzadegan2014@gmail.com;

a_bahmanzade@yahoo.com. many therapeutic indications. Leaves and their essential oil increase gastric fluid secretion and work against digestive disorders such as flatulent colic [6]. Anticonvulsive and antiepileptic activities [7] of the leaf extract have been confirmed. Recently Simic et al. [8] tested the antioxidative activity of methanolic extracts of leaves, bark and fruits. The most significant activity was obtained with the bark extract. The volatile compounds of wood and bark of this species have been studied [9]. Monoterpenes (in particular 1, 8-cineole and eugenol) were identified as the main class constituent in the bark oil, whereas sesquiterpenes (dehydrocostunolide) were the most important constituents of the wood extract. Fang et al. [10] reported their results concerning the isolation of six sesquiterpene lactones from the methanol extract of dried leaves of $L$. nobilis, responsible for inducing apoptosis. The leaf essential oil of the species under investigation showed also a very strong antibacterial 
activity against foodborne pathogens [11]. Moreover, pharmacological activity, which includes antifungal, anti-diabetic, and anti-inflammatory activities [10], has been also demonstrated. The chemical composition of the leaf essential oil obtained from different methods of isolation, were extensively studied by many researchers [12-16]. Generally, the yield and composition of the oil varies, depending upon the origin, the collection period, and the growth stage of the plant [17]. The study of the seasonal and geographical variation in yield and composition of leaf essential oil of $L$. nobilis collected from various areas in Tunisia showed that a seasonal variation both in yield and composition revealed, whereas geographical variability did not pronounce, and no chemotypes observed [18]. Seasonal variation in oil composition of L. nobilis grown in Portugal showed that during the period of highest essential oil yield (end of August), lower percentages of hydrocarbons and higher percentages of oxygenated compounds found [19]. Phenolic compounds in plants provide an array of natural sources of antioxidants for use in foods and nutraceuticals. Since natural sources contain a variety of phenolic compounds with varying antioxidant activity and exert their effects via different mechanisms, their efficacy in bulk oils, emulsions and composite foods might be greater than that of individual compounds. Furthermore, in addition to their safety advantages, food phenolics may augment body's source of natural antioxidants [20]. Phenols are able to donate $\mathrm{H}$-atoms of phenol hydroxyl groups in reaction with peroxyl radicals that can produce stabilized phenoxyl radicals, thus terminating lipid peroxidation chain reactions. The antioxidant activity of phenols depends on the electronic and steric effects of the ring, substituents, and the strength of hydrogen-bonding interactions between the phenol and the solvent [21-23]. A few papers have dealt with the antioxidant activity and phenolic constituents of laurel leaves [24-27]. As a sample the antioxidant activity of the oil of $L$. nobilis collected in Tunisia found more effective than the synthetic antioxidant (BHT) at 200 ppm and could be attributed to the active compounds eugenol, elemicin and methyl eugenol present in this essential oil [28]. But there is no previous study on the seasonal changes of polyphenol content and antioxidant activity in this plant. The objective of this study was to investigate the seasonal changes in the chemical composition of oil, polyphenol content and antioxidant activity in extract of L. nobilis.

\section{Materials and Methods}

\subsection{Collection of Plants and Identification}

Fresh leaves of $L$. nobilis were collected from its wild habitat Eram garden, Fars province, in the middle of spring, summer, autumn, and winter (2013-2014; Table 1) for determination of oil concentration, chemical constituents and anti oxidant activity. Voucher specimen was deposited at the Herbarium of Fars Research center for agriculture, Shiraz, Iran.

\subsection{Preparation of EO and Crude Extract}

The plants were shaded at room temperature $\left(20-25{ }^{\circ} \mathrm{C}\right)$. The EOs of all dried samples $(100 \mathrm{~g})$ were isolated by hydrodistillation for $3 \mathrm{~h}$, using a Clevenger-type apparatus according to the method recommended in British Pharmacopoeia [29]. This work was repeated three times. An average of the oils yield was calculated. The distillated oils were dried over anhydrous sodium sulfate and stored in tightly

Table 1 Oil yields, statistical analysis of oil and antioxidant activity in extract of $L$. nobilis.

\begin{tabular}{lllll}
\hline Species & Collection dates & Oil yield $(\%)$ & Duncan's mean separation* & Antioxidante activity $(\mu \mathrm{g} / \mathrm{mL})$ \\
\hline \multirow{4}{*}{ Laurus nobilis } & Spring. May, 2012 & 0.87 & C & 268.6 \\
& Summer. August, 2012 & 1.3 & B & 672.5 \\
& Autumn. November, 2012 & 1.0 & BC & 418.1 \\
& Winter. January, 2013 & 2.1 & A & 702.1 \\
\hline
\end{tabular}


*Oil yields within season followed by the same letter are not significantly different at $P<0.01$.

closed dark vials until analysis. For extract preparation, the dried plants materials were ground into powder by using a hand mill. The powdered plants ( $30 \mathrm{~g})$ extracted using $100 \mathrm{~mL}$ of methanol by maceration method [29]. The crude extracts were concentrated in vacuo at $40^{\circ} \mathrm{C}$ using a rota vapor.

\subsection{Oil Analysis Procedure}

GC analysis was performed using an Agilent gas chromatograph series 7890-A with an FID (flame ionization detector). The analysis was carried out on fused silica capillary HP-5 column $(30 \mathrm{~m} \times 0.32 \mathrm{~mm}$ i.d.; film thickness $0.25 \mu \mathrm{m}$ ). The injector and detector temperatures were kept at $250{ }^{\circ} \mathrm{C}$ and $280{ }^{\circ} \mathrm{C}$, respectively. Nitrogen was used as carrier gas at a flow rate of $1 \mathrm{~mL} / \mathrm{min}$; oven temperature program was $60-210{ }^{\circ} \mathrm{C}$ at the rate of $4{ }^{\circ} \mathrm{C} / \mathrm{min}$ and then programmed to $240{ }^{\circ} \mathrm{C}$ at the rate of $20{ }^{\circ} \mathrm{C} / \mathrm{min}$ and finally held isothermally for $8.5 \mathrm{~min}$; split ratio was 1:50. GC-MS analysis was carried out by use of Agilent gas chromatograph equipped with fused silica capillary HP-5MS column $(30 \mathrm{~m} \times 0.25 \mathrm{~mm}$ i.d.; film thickness $0.25 \mu \mathrm{m}$ ) coupled with an Agilent mass spectrometer series 5975-C. Helium was used as carrier gas with ionization voltage of $70 \mathrm{eV}$. Ion source and interface temperatures were $230{ }^{\circ} \mathrm{C}$ and $280{ }^{\circ} \mathrm{C}$, respectively. Mass range was from 45 to $550 \mathrm{amu}$. Oven temperature program was the same given above for the GC.

\subsection{Identification of Compounds}

The constituents of the EOs were identified by calculation of their retention indices under temperature-programmed conditions for n-alkanes (C8-C25) and the oil on a HP-5 column under the same chromatographic conditions. Identification of individual compounds was made by comparison of their mass spectra with those of the internal reference mass spectra library or with authentic compounds and confirmed by comparison of their retention indices with authentic compounds or with those of reported in the literature [30]. For quantification purpose, relative area percentages obtained by FID were used without the use of correction factors.

\subsection{Extraction of Polyphenol and HPLC Analysis}

The procedure for extraction of polyphenols was carried out according to the modified method established by Justesen [31]. Reference standard of 10 polyphenols (gallic acid, catechin, chlorogenic acid, caffeic acid, quercetin, cinnamic acid, coumarin, p-comaric acid, rutin and carvacrol) were purchased from Merck (Darmstadt, Germany). HPLC analysis was carried out on an Agilent 1200 series, equipped with a Zorbax Eclipse XDB-C18 column $(4.6 \times 5 \mu \mathrm{m}$ i.d.; $\times 150 \mathrm{~mm}$ film thickness, RP), and a PDA (photodiode array detector). Elution was monitored at 280 and $230 \mathrm{~nm}$. The column temperature was $30^{\circ} \mathrm{C}$. The injection volume was selected $20 \mu \mathrm{L}$ and it was done automatically using autosampler. The total running time was $30 \mathrm{~min}$. Gradient elution was applied to achieve maximum separation and sensitivity. The elution was performed by varying the proportion of solvent A (formic acid $1 \%$ in deionized water) to solvent B (Methanol $(\mathrm{v} / \mathrm{v}))$ as follows: Methanol:formic acid 1\% (10:90), at 0 min; Methanol: formic acid 1\% (25:75), at $10 \mathrm{~min}$; Methanol:formic acid 1\% (60:40), at $20 \mathrm{~min}$. And finally, Methanol:formic acid 1\% (70:30), at $30 \mathrm{~min}$. Linear calibration graphs were obtained with good correlation for standard solutions .

\subsection{Determination of Antioxidant Activity by the DPPH} Radical Scavenging Method

The antioxidant activity of plants extract and the standard antioxidant (gallic acid) were assessed on the basis of radical scavenging effect of the stable DPPH (1, 1-Diphenyl-2-picrylhydrazyl) free radical, according to a modified method [32]. The DPPH radical inhibition was measured at $515 \mathrm{~nm}$ by using a micro-plate reader model biotek ELx 808. The $\mathrm{IC}_{50}$ of 
each sample (concentration in $\mu \mathrm{g} / \mathrm{mL}$ required to inhibit DPPH radical formation by 50\%) was calculated by Matlab software (Table 1).

\subsection{Statistical Analysis}

Statistical analyses were done using SAS software. Means were separated with a $t$-test for comparison of oil content (Table 1) and main classes (Table 2) of leaves from the L. nobilis among the seasons. A value of $P<0.01$ was considered statistically significant.

\section{Results}

The oils isolated from the leaves of L. nobilis were achieved by hydrodistillation method. An analysis of variance indicated significant differences in oil content among the seasons $(P<0.01$; Table 1$)$ and between the main classes $(P<0.01$; Table 2$)$. The best harvesting time for high oil levels was winter (Fig. 1). From 71 compounds identified in the oil of $L$. nobilis, included 1 , 8-cineole $\quad(5.7 \%-42.6 \%), \quad \alpha$-terpinyl acetate $(3.2 \%-13.1), \quad$ sabinene $(2.3 \%-12.0 \%), \quad \beta$-elemene $(0.2 \%-17.7 \%)$ and (E)-caryophyllene $(0.2 \%-16.9 \%$; Table 2) as major components. The maximum percentage of 1,8-cineole was recorded in winter, with an increase in the cineole content from spring to summer, a decrease to autumn and an increase in winter.

For leaves of $L$. nobilis, the minimum percentage of -terpinyl acetate and sabinene occurred as same as cineole content in the spring (3.2\% and $2.3 \%)$ and the maximum one achieved in the summer $(13.1 \%$ and $12.0 \%$ ). The other major oil components such as

Table 2 Essential oils composition and statistical analysis of main constituents of $L$. nobilis in different seasons.

\begin{tabular}{|c|c|c|c|c|c|c|}
\hline & & & Spring & Summer & Autumn & Winter \\
\hline No. & Compound & $\mathbf{R I}^{\mathbf{a}}$ & & $(\%) \mathrm{b}$ & & \\
\hline 1 & Tricyclene & 919 & $\mathrm{t}$ & $\mathrm{t}$ & - & - \\
\hline 2 & $\alpha$-Thujene & 923 & 0.2 & 0.9 & 0.8 & 0.4 \\
\hline 3 & $\alpha$-Pinene & 930 & 2.5 & 5.2 & 3.9 & 4.6 \\
\hline 4 & Camphene & 945 & 0.7 & 0.3 & 0.6 & 0.4 \\
\hline 5 & Sabinene & 970 & 2.3 & 12.0 & 8.2 & 10.4 \\
\hline 6 & $\beta$-Pinene & 974 & 1.6 & 4.2 & 2.7 & 3.6 \\
\hline 7 & Myrcene & 987 & 0.6 & 1.5 & 2.3 & 1.5 \\
\hline 8 & $\alpha$-Phellandrene & 1003 & 0.6 & 1.3 & 3.5 & 1.6 \\
\hline 9 & $\delta$-3-Carene & 1008 & 0.08 & 0.1 & 0.2 & 0.1 \\
\hline 10 & $\alpha$-Terpinene & 1013 & 0.2 & 0.7 & 0.5 & 0.2 \\
\hline 11 & p-Cymene & 1021 & 0.09 & 1.0 & 0.1 & 0.6 \\
\hline 12 & Limonene & 1026 & 0.7 & 2.9 & - & - \\
\hline 13 & $\beta$-Phellandrene & 1030 & - & - & 0.3 & 1.7 \\
\hline 14 & 1,8-Cineole & 1031 & 5.7 & 37.5 & 20.3 & 42.6 \\
\hline 15 & (Z)- $\beta$-Ocimene & 1033 & 0.1 & $\mathrm{t}$ & - & - \\
\hline 16 & (E)- $\beta$-Ocimene & 1043 & 1.1 & 0.1 & 0.2 & 0.05 \\
\hline 17 & $\gamma$-Terpinene & 1054 & 0.3 & 1.2 & 0.8 & 0.5 \\
\hline 18 & cis-Sabinene hydrate & 1062 & $\mathrm{t}$ & 0.6 & 0.9 & 0.4 \\
\hline 19 & Terpinolene & 1084 & 0.1 & 0.6 & 0.4 & 0.2 \\
\hline 20 & Linalool & 1096 & 0.6 & 3.7 & 2.5 & 1.9 \\
\hline 21 & cis-p-Menth-2-en-1-ol & 1123 & - & - & 0.2 & 0.1 \\
\hline 22 & trans-p-Menth-2-en-1-ol & 1140 & - & - & 0.1 & 0.1 \\
\hline 23 & $\delta$-Terpineol & 1163 & $\mathrm{t}$ & 0.4 & 0.9 & 0.5 \\
\hline 24 & Terpinene-4-ol & 1173 & 0.2 & 1.6 & 2.0 & 1.6 \\
\hline 25 & $\alpha$-Terpineol & 1187 & 0.3 & 2.0 & 5.4 & 3.0 \\
\hline 26 & Nerol & 1230 & - & - & 0.3 & 0.4 \\
\hline 27 & Linalyl acetate & 1252 & $\mathrm{t}$ & 0.2 & - & - \\
\hline
\end{tabular}


Activity in Extract of Laurus nobilis Grown in Iran

\begin{tabular}{|c|c|c|c|c|c|c|}
\hline 28 & Bornyl acetate & 1282 & 0.6 & 0.3 & 0.8 & 0.3 \\
\hline 29 & 2-Undecanone & 1289 & 0.1 & 0.2 & 0.1 & 0.07 \\
\hline \multicolumn{7}{|c|}{ (Table 2 continued) } \\
\hline & & & Spring & Summer & Autumn & Winter \\
\hline No. & Compound & $\mathbf{R I}^{\mathbf{a}}$ & & $(\%) \mathrm{b}$ & & \\
\hline 30 & neo iso-Isopulegyl acetate & 1319 & - & - & 1.0 & 0.6 \\
\hline 31 & $\delta$-elemene & 1333 & 0.8 & $\mathrm{t}$ & - & - \\
\hline 32 & $\alpha$-terpinyl acetate & 1347 & 3.2 & 13.1 & 13.0 & 10.6 \\
\hline 33 & Eugenol & 1353 & 0.1 & 0.8 & 6.9 & 3.4 \\
\hline 34 & Neryl acetate & 1361 & 0.2 & 0.3 & 0.6 & - \\
\hline 35 & $\alpha$-ylangene & 1367 & 0.4 & $\mathrm{t}$ & 0.2 & - \\
\hline 36 & $\alpha$-copaene & 1372 & 0.1 & $\mathrm{t}$ & - & - \\
\hline 37 & Geranyl acetate & 1387 & - & - & 0.3 & 0.08 \\
\hline 38 & $\beta$-elemene & 1394 & 17.7 & 0.2 & 2.0 & 0.8 \\
\hline 39 & Methyl eugenol & 1404 & 0.5 & 3.3 & 5.5 & 2.7 \\
\hline 40 & $\alpha$-gurjunene & 1407 & 0.2 & - & - & - \\
\hline 41 & (E)-caryophyllene & 1422 & 16.9 & 0.2 & 1.7 & 0.9 \\
\hline 42 & $\beta$-copaene & 1426 & 0.1 & - & - & - \\
\hline 43 & $\alpha$-guaiene & 1435 & 1.0 & - & 0.2 & 0.09 \\
\hline 44 & Aromadendrene & 1441 & - & - & 0.3 & - \\
\hline 45 & (E)-cinamyl acetate & 1447 & - & - & 0.3 & - \\
\hline 46 & (E)-isoeugenol & 1451 & - & - & 0.8 & 0.1 \\
\hline 47 & $\alpha$-humulene & 1454 & 2.8 & $\mathrm{t}$ & 0.3 & 0.1 \\
\hline 48 & (E)- $\beta$-farnesene & 1457 & 0.8 & $\mathrm{t}$ & - & - \\
\hline 49 & allo-aromadendrene & 1460 & - & - & 0.2 & - \\
\hline 50 & Germacrene D & 1479 & 4.8 & 0.08 & 0.9 & 0.2 \\
\hline 51 & $\beta$-selinene & 1490 & 0.7 & 0.07 & 0.4 & 0.2 \\
\hline 52 & (E)-methyl isoeugenol & 1492 & & 0.1 & - & - \\
\hline 53 & $\alpha$-selinene & 1498 & 4.8 & - & - & - \\
\hline 54 & Bicyclogermacrene & 1500 & 2.3 & - & 0.7 & 0.06 \\
\hline 55 & Cuparene & 1505 & - & - & 0.2 & 0.1 \\
\hline 56 & $\alpha$-bulnesene & 1508 & - & - & 0.6 & 0.2 \\
\hline 57 & $\gamma$-cadinene & 1511 & 0.9 & 0.07 & 0.5 & 0.1 \\
\hline 58 & $\delta$-cadinene & 1520 & 1.4 & 0.1 & 0.4 & - \\
\hline 59 & (E)- $\gamma$-bisabolene & 1532 & 13.1 & 0.08 & - & - \\
\hline 60 & 10-epi-cubebol & 1538 & - & - & 0.2 & 0.3 \\
\hline 61 & Elemol & 1549 & 0.8 & 0.1 & 0.6 & 0.1 \\
\hline 62 & Elemicin & 1555 & - & $\mathrm{t}$ & 0.3 & 0.08 \\
\hline 63 & Germacrene D-4-ol & 1573 & 0.6 & $\mathrm{t}$ & - & - \\
\hline 64 & Spathulenol & 1575 & - & 0.3 & 0.9 & 0.4 \\
\hline 65 & Caryophyllene oxide & 1580 & 0.8 & 0.3 & 0.4 & 0.6 \\
\hline 66 & Viridiflorol & 1588 & 0.2 & 0.06 & - & - \\
\hline 67 & Humulane-1,6-dien-3-ol & 1619 & - & - & 0.4 & 0.2 \\
\hline 68 & 1,10-di-epi-cubenol & 1621 & - & - & 0.5 & - \\
\hline 69 & $\beta$-eudesmol & 1648 & 1.3 & 0.4 & 0.6 & 0.3 \\
\hline 70 & $\alpha$-eudesmol & 1650 & - & 0.2 & 0.6 & 0.1 \\
\hline \multirow[t]{5}{*}{71} & $\alpha$-cadinol & 1652 & 2.2 & 0.2 & - & - \\
\hline & Monoterpene hydrocarbons & & $8.6^{\mathrm{c}} \mathrm{C}^{\mathrm{d}}$ & $11.5 \mathrm{D}$ & $68.8 \mathrm{~A}$ & $5.9 \mathrm{~A}$ \\
\hline & Oxygenated monoterpenes & & $32 \mathrm{~A}$ & $64.1 \mathrm{~B}$ & $0.8 \mathrm{D}$ & $1.6 \mathrm{D}$ \\
\hline & Sesquiterpene hydrocarbons & & $24.5 \mathrm{~B}$ & $61.9 \mathrm{C}$ & $8.6 \mathrm{~B}$ & $4.2 \mathrm{~B}$ \\
\hline & Oxygenated sesquiterpenes & & $25.8 \mathrm{~B}$ & $68.5 \mathrm{~A}$ & $2.7 \mathrm{C}$ & $2.0 \mathrm{C}$ \\
\hline
\end{tabular}

\footnotetext{
${ }^{\mathrm{a}} \mathrm{RI}=$ Retention indices in elution order from HP-5 column.
} 
${ }^{\mathrm{b}} \mathrm{t}=$ trace $(<0.05)$; nd: not detected.

${ }^{c} \%$ of main constituents within season followed by the same letter are not significantly different at $P<0.01$.

dDuncan's mean separation.

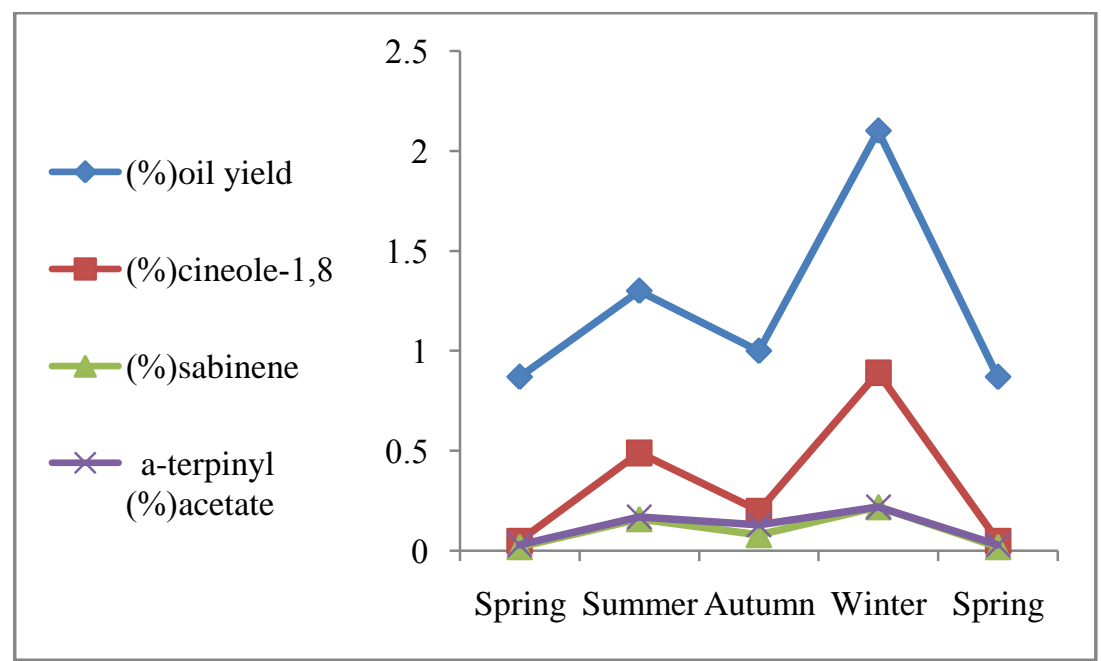

Fig. 1 Percentage of oil and main components of $L$. nobilis in different seasons.

Table 3 Phenolic compound of $L$. nobilis in different seasons.

\begin{tabular}{|c|c|c|c|c|}
\hline & Spring & Summer & Autumn & Winter \\
\hline Polyphenol & & Amount $^{\mathrm{a}}$ & & \\
\hline Gallic acid & $\mathrm{nd}^{\mathrm{b}}$ & nd & nd & nd \\
\hline Catechin & nd & nd & nd & nd \\
\hline Caffeic acid & nd & nd & nd & nd \\
\hline Chloregenic acid & nd & nd & nd & nd \\
\hline Quercetin & $0.03 \pm 0.006$ & $0.019 \pm 0.001$ & $0.004 \pm 0.001$ & $0.001 \pm 0.0006$ \\
\hline Cinnamic acid & $3.0 \pm 1.00$ & $2.1 \pm 0.058$ & $2.9 \pm 0.058$ & $2.7 \pm 0.100$ \\
\hline Coumarin & $0.02 \pm 0.006$ & $0.002 \pm 0.0006$ & $0.02 \pm 0.006$ & $0.001 \pm 0.0006$ \\
\hline p-Comaric acid & nd & nd & nd & nd \\
\hline Rutin & nd & nd & nd & nd \\
\hline Carvacrol & $0.5 \pm 0.058$ & $0.07 \pm 0.006$ & $0.4 \pm 0.058$ & $0.05 \pm 0.006$ \\
\hline
\end{tabular}

${ }^{a}$ Calculated mean amount of the polyphenol $(\mathrm{mg} / \mathrm{g})$ based on the weight of the ground dry plant in three replicates \pm SD.

${ }^{\mathrm{b}}$ nd: not detected.

$\delta$-elemene and (E)-caryophyllene differed with the change in seasons. The minimum amount of $\delta$-elemene and (E)-caryophyllene was observed in the summer $(0.2 \%$ and $0.2 \%)$ and the maximum one determined in the spring $(17.7 \%$ and $16.9 \%)$. The predominant phenolic constituents in L. nobilis were cinnamic acid, carvacrol, quercetin and coumarin, respectively. Gallic acid, catechin, caffeic acid, chloregenic acid, p-Comaric acid and rutin were not detected in any seasons (Table 3). Investigation of antioxidant activity showed the best activity in spring $(268.6 \mu \mathrm{g} / \mathrm{mL})$ and the worst one was observed in winter $(702.1 \mu \mathrm{g} / \mathrm{mL})$ for leaves extract of $L$. nobilis. Although, the maximum percentage of 1, 8-cineole and oil yield were recorded in winter, but the antioxidant activity followed the reverse trend. The antioxidant activity was varied in the different season (Table 1). Our study showed that there was a correlation between the antioxidant capacity and phenolic compounds cinnamic acid and carvacrol (Fig. 2). With decreasing in cinnamic acid and carvacrol content from spring to summer, the antioxidant activity also decreased. From summer to autumn the amount of the two phenolic compounds and antioxidant capacity increased and then decreased both of them during the period autumn-winter. 
All considered EOs were characterized by a clear predominance of oxygenated compounds especially monoterpenes and sesquiterpenes, respectively. Also, the concentration of oxygenated monoterpenes was
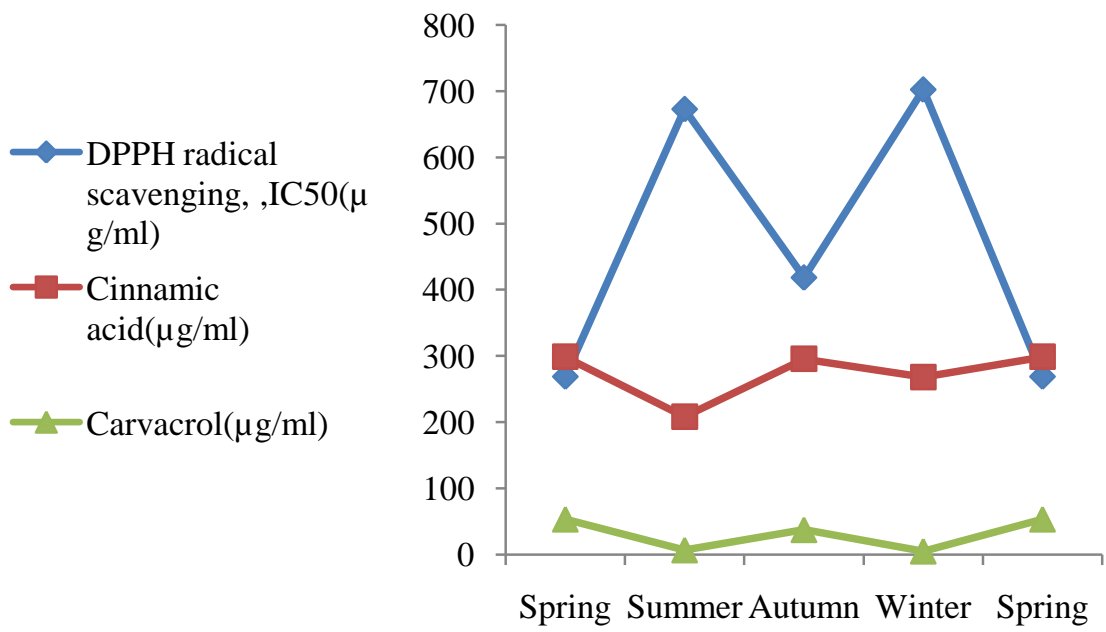

Fig. 2 Correlation between antioxidant activity, cinnamic acid and carvacrol content of $L$. nobilis extract in different seasons.

varied during the seasons (Table 2). The trend of this class was because of cineole content. In general, winter was the season with higher in the EO and 1, 8-cineole. The 1, 8-cineole content was not significant in spring. The highest and lowest amount of monoterpene hydrocarbons $(8.6 \%-32 \%)$ found in the spring and summer, oxygenated monoterpenes, occurred in the spring and winter (11.5\%-68.5\%), sesquiterpene hydrocarbons found in the summer and spring (0.8\%-68.8\%) and oxygenated sesquiterpenes followed the same trend sesquiterpene hydrocarbons in the summer and spring (1.6\%-5.9\%), respectively. In the spring, there are a maximum amount of sesquiterpene hydrocarbons because of the high level of $\beta$-elemene (17.7\%), (E)-caryophyllene (16.9\%), (E)- $\gamma$-bisabolene $(13.1 \%)$, Germacrene D (4.8\%) and $\alpha$-selinene (4.8\%), respectively. The amount of these compounds was not remarkable in other seasons. Sabinene (12.0\%), $\alpha$-pinene (5.2\%), $\beta$-pinene (4.2\%) and limonene $(2.9 \%)$ were responsible for the highest amount of monoterpene hydrocarbons in summer.

\section{Discussion}

Similar results are reported that a seasonal variation both in yield and composition of $L$. nobilis has been revealed [18]. By comparison with our research, all essential oils considered in a previous study have been characterized by a predominance of oxygenated compounds especially monoterpenes, phenylpropanoids and sesquiterpenes, respectively. The concentration of this class (specially oxygenated phenylpropanoids) has been decreased during the period October-July [18]. Another study has been showed that the essential oil recovery increased in early June, reached a maximum in late July, and constantly decreased thereafter [16]. Putievsky et al. detected that the content of essential oil in fresh leaves from cultivated trees of $L$. nobilis reached the highest level in autumn, while the lowest one was observed in late spring [15]. It is difficult to see the accordance of the results in literature on antioxidant activity because of the usage of the different testing methods. The lower free radical scavenging activity values was obtained from L. nobilis (1.901, $\mathrm{IC}_{50},[\mathrm{mg} / \mathrm{mL}]$ ), in Konya [33]. The antioxidant activity of the L. nobilis floral buds oil collected in Tunisia was more effective than the synthetic antioxidant BHT (butylated hydroxytoluene), at $200 \mathrm{ppm}$ [28]. The antioxidant capacity was determined by a common used and highly accepted method. However, it was clearly noted that, there are a 
lot of variables affect on antioxidant activity in the literature [18]. Therefore, the numerous of antioxidant activity methods makes it necessary to use more than one method in such studies.

\section{Conclusions}

In conclusion, a seasonal variation in yield and composition of Laurus nobili oil has been observed. The seasonal variation of 1,8 -cineole in the oil of $L$. nobilis was remarkable. A terpenoid oxide, 1, 8-cineole is present in many plant essential oils and displays an inhibitory effect on some types of experimental inflammation in rats, such as paw edema induced by carrageenan and cotton pellet-induced granuloma. The 1, 8-cineole also has antimicrobial, antiinflammatory and antinociceptive effects [34]. Further research is needed on the determination of the correlation between the antioxidant capacity and the chemical composition of the plants oil. But, the presence of phenolic compounds in the plant extracts contributes significantly to their antioxidant potential. Antioxidant properties of these compounds are directly related to their structure. Indeed, phenolics are composed of one (or more) aromatic rings with one or more hydroxyl groups which are able to quench free radicals by forming resonance-stabilized phenoxyl radicals [35, 36].

In this study, it was concluded that the methanol extract of L. nobilis in spring could be have the best antioxidant activity because of the high amount of phenolic compounds. Further investigation of total phenol and flavonoid contents and in vivo antioxidant activities is needed.

\section{Acknowledgments}

The authors wish to thanks to Fars Research Center for Agriculture and Natural Resources for financial support of this work.

\section{References}

[1] Hogg, J. W., Terhune, S. J., and Lawrenc, B. M. 1974. "Dehydro-1.8-Cineole: A New Monoterpene Oxide in
Laurus noblis Oil." Phytochemistry 13 (5): 868-9.

[2] Zargari, A. 1990. Medicinal Plants. Iran: Tehran University Press, 325-8.

[3] Aqili-khorasani, M. S. 1992. Collection of Drugs (Material Medica). Iran: Tehran, Enghelab-e-Eslami Publishing and Educational Organization, 624-30.

[4] Qamar, S., and Chaudhary, F. M. 1991. "Antifungal Activity of Some Essential Oils from Local Plants." Pakistan Journal of Scientific and Industrial Research 34 (1): 30-1.

[5] Seyed, M., Riaz, M., and Chaudhary, F. M. 1991. "The Antibacterial Activity of the Essential Oil of the Pakistani Acotus Calmus, Callistemon Lanceolatus and Laurus nobilis." Pakistan Journal of Scientific and Industrial Research 34 (11): 456-8.

[6] Matsuda, H., Shimoda, H., Ninomiya, K., and Yoshikawa, M. 2002. "Inhibition Mechanism of Costunolide, a Sesquiterpene Lactone Isolated from Laurus nobilis, on Blood-Ethanol Elevation in Rats: Involvement of Inhibition of Gastric Emptying and Increase in Gastric Juice Secretion." Alcohol and Alcoholism 37 (2): 121-7.

[7] Sayyah, M., Vaizadeh, J., and Kamalinejad, M. 2002. "Anticonvulsant Activity of the Leaf Essential Oil of Laurus nobilis Against Pentylenetetrazole and Maximal Electroshock-Induced Seizures." Phytomedicine 9 (3): 212-6.

[8] Simic, M., Kundakovic, T. K., and Kovacevi, N. 2003. "Preliminary Assay on the Antioxidantive Activity of Laurus nobilis Extracts." Fitoterapia 74 (6): 613-6.

[9] Kilic, A., and Altunas, E. 2006. "Wood and Bark Volatile Compounds of Laurus nobilis L." Holz als Roh-und Werkstoff 64: 317-20.

[10] Fang, F., Sang, S., Che, K. Y., Gosslau, A., Ho, C. T., and Rosen, R. T. 2005. "Isolation and Identification of Cytotoxic Compounds from Bay Leaf (Laurus nobilis)." Food Chemistry 93 (3): 497-501.

[11] Dadalioglu, I., and Evrendilek, G. U. 2004. "Chemical Compositions and Antibacterial Effects of Essential Oils of Turkish Oregano (Origanum minutiflorum), Bay Laurel (Laurus nobilis), Spanish Lavender (Lavandula stoechas L.) and Fennel (Foeniculum vulgare) on Common Foodborne Pathogens." Journal of Agricultural and Food Chemistry 52 (26): 8255-60.

[12] Caredda, A., Marongiu, B., Porcedda, S., and Soro, C. 2002. "Supercritical Carbon Dioxide Extraction and Characterization of Laurus nobilis Essential Oil." Journal of Agricultural and Food Chemistry 50 (6): 1492-6.

[13] Marzouki, H., Khaldi, A., Chamli, R., Bouzid, S., Piras, A., Falconieri, D., and Marongiu, B. 2009. "Biological Activity Evaluation of the Oils from Laurus nobilis of Tunisia and Algeria Extracted by Supercritical Carbon Dioxide." Natural Products Research 23 (3): 230-7. 
[14] Marzouki, H., Piras, A., Salah, K. B., Medini, H., Pivetta, T., Bouzid, S., Marongiu, B., and Falconieri, D. 2009. "Essential Oil Composition and Variability of Laurus nobilis L. Growing in Tunisia, Comparison and Chemometric Investigation of Different Plant Organs." Natural Products Research 23 (4): 343-54.

[15] Putievsky, E., Ravid, U., Snir, N., and Sanderovich, D. 1984. "The Essential Oils from Cultivated Bay Laurel." Israel Journal of Botany 33 (1): 47-52.

[16] Riaz, M., Ashraf, C. M., and Chaudhary, F. M. 1989. "Studies of the Essential Oil of the Pakistani Laurus nobilis LINN in Different Seasons." Pakistan Journal of Scientific and Industrial Research 32 (1): 33-5.

[17] Shiyab, S., Shatnawi, M., Shibli, R., Al-zweiri, M., Akash, M., and Aburijai, T. 2012. "Influence of Developmental Stage on Yield and Composition of Origanum syriacum $L$. Oil by Multivariate Analysis." Journal of Medicinal Plants Research 6 (15): 2985-94.

[18] Marzouki, H., Elaissi, A., Khaldi, A., Bouzid, S., Falconieri, D., Marongiu, B., Piras, A., and Porcedda, S. 2009. "Seasonal and Geographical Variation of Laurus nobilis L. Essential Oil from Tunisia." The Open Natural Products Journal 2: 86-91.

[19] Odete, R. 1989. "Seasonal Variation in Oil Composition of Laurus nobilis Grown in Portugal." Journal of Essential Oil Research 1 (4): 199-200.

[20] Shahidi, F. 2000. "Antioxidants in Food and Food Antioxidants." Nahrung Food 44 (3): 158-63.

[21] Lucarini, M., Mugnaini, V., and Pedulli, G. F. 2002. "Bond Dissociation Enthalpies of Polyphenols: The Importance of Cooperative Effects." Journal of Organic Chemistry 67 (3): 928-31.

[22] Snelgrove, D. W., Lusztyk, J., Banks, J. T., Mulder, P., and Ingold, K. U. 2001. "Kinetic Solvent Effect on Hydrogen-Atom Abstractions: Reliable, Quantitative Predictions via a Single Empirical Equation.” Journal of American Chemical Society 123 (1): 469-77.

[23] Avila, D. V., Ingold, K. U., Lusztyk, J., Green, W. H., and Procopio, D. R. 1995. "Dramatic Solvents Effects on the Absolute Rate Constants for Abstraction of the Hydroxylic Hydrogen Atom from Tert-butylhydroperoxide and Phenol by the Cumyloxyl Radical - the Role of Hydrogen Bonding." Journal of American Chemical Society 117 (10): 2929-30.

[24] Speroni, E., Cervellati, R., Dall'Acqua, S., Guerra, M. C., Greco, E., Govoni, P., and Innocenti, G. 2011. "Gastroprotective Effect and Antioxidant Properties of Different Laurus nobilis L. Leaf Extracts." Journal of
Medicinal Food 14 (5): 499-504.

[25] Dudonne, S., and Vitrac, X. 2009. "Coutiere Properties and Total Phenolic Content of 30 Plant Extracts of Industrial Interest Using DP and ORAC Assays." Journal of Agricultural and Food Chemistry 57 (5): 1768-74.

[26] Ferreira, A., and Proenca, C. 2006. "Serralheiro Acetylcholinesterase Inhibition and Antioxidant Activity of Medicinal Plants from Portugal." Ethnopharmacology 108: 31-7.

[27] Dall'Acqua, S., Cervellati, R., Speroni, E., Costa, S., Guerra, M. C., Stella, L., Greco, E., and Innocenti, G. 2009. "Phytochemical Composition and Antioxidant Activity of Laurus nobilis L. Leaf Infusion." Journal of Medicinal Food 12 (4): 869-76.

[28] Bouzouita, N., ElOmri, A., Kachouri, F., Wathelet, J. P., Marlier, M., and Chaabouni, M. M. 2009. "Chemical Composition and Antioxidant Activity of Laurus nobilis Floral Buds Essential Oil." Journal of Essential Oil and Bearing Plants 12 (6): 694-702.

[29] British pharmacopoeia.1988. British Pharmacopoeia. London: HMSO, 137-8.

[30] Adams, R. 2001. Identification of Essential Oil Components by Gas Chromatography Quadrupole Mass Spectroscopy. Carol Stream, USA: Allured Publishing Corporation.

[31] Justesen, U., Knuthsen, P., and Leth, T. 1998. "Quantitative Analysis of Flavonols, Flavones and Flavanons in Fruits, Vegetables and Beverages by HPLC with Photodiode Array and Mass Spectrometric Detection." J Chromatography A. 799 (1-2): 101-10.

[32] Bruits, M., Asres, k., and Bucar, F. 2001. "The Antioxidant Activity of the Essential Oils of Artemisia Afra, Artemisia byssinica and Juniperus procera." Phytotherapy Research 15 (2): 103-8.

[33] Unver, A., Arslan, D., Ozcan, M. M., and Akbulut, M. 2009. "Phenolic Content and Antioxidant Activity of Some Spices.” World Applied Sciences Journal 6 (3): 373-7.

[34] Santos, F. A., and Roa, V. S. N. 2000. "Anti-inflammatory and Antinociceptive Effects of 1,8-Cineole a Terpenoid Oxid Present in Many Plants Essential Oils." Phytotherapy Research 14 (4): 240-4.

[35] Rice-Evans, C. A., Miller, N. J., and Paganga, G. 1996. "Structure-Antioxidant Capacity Relationships of Flavonoids and Phenolic Acid." Free Radical Biology and Medicine 20 (7): 933-56.

[36] Bors, W., and Michel, C. 2002. "Chemistry of the Antioxidant Effect of Polyphenols." Annals of the New York Academy of Sciences 957: 57-69. 